\title{
Labyrinthe
}

40 | 2013

Comme les abeilles

\section{L'abeille et la ruche comme métaphores politiques}

\section{Ariel Kyrou}

\section{OpenEdition}

Journals

Édition électronique

URL : http://journals.openedition.org/labyrinthe/4326

DOI : $10.4000 /$ labyrinthe.4326

ISSN : 1950-6031

Éditeur

Hermann

Édition imprimée

Date de publication : 1 mars 2013

Pagination : 115-117

ISBN : 9782705688400

\section{Référence électronique}

Ariel Kyrou, «L'abeille et la ruche comme métaphores politiques », Labyrinthe [En ligne], 40 | 2013, mis

en ligne le 01 mars 2015, consulté le 30 avril 2019. URL : http://journals.openedition.org/

labyrinthe/4326 ; DOI : 10.4000/labyrinthe.4326 


\section{L'abeille et la ruche comme métaphores politiques}

Ariel KYrou

Dans le monde de la culture, la métaphore des abeilles doit, comme les autres métaphores des insectes, être maniée avec une certaine nuance. Les romans de science-fiction qui mettent en scène le monde des insectes le font assez rarement de façon positive, ou alors à la marge: l'exemple de romancier de science-fiction parmi les plus connus qui a utilisé la métaphore des insectes, c'est Frank Herbert, l'auteur de Dune - ce monde lui-même étant marqué par la logique souterraine d'un certain type d'animaux. Après Dune, il a écrit un roman, La Ruche d'Hellstrom (1973), où il met en scène une société humaine appelée « la ruche », mais inspirée du monde des fourmis autant que de celui des abeilles. Le premier rapport de celui qui lit le livre est un rapport d'effroi : dans la ruche, tout est partagé, au point que, lorsque l'un des humains habitant la ruche meurt, il est mangé, recyclé, comme dans le film Soleil vert (1973). Il y a toutes sortes de partages des membres du corps des êtres décédés de cette société pour le bénéfice des vivants et plus largement du groupe dans son ensemble. Cette logique de la collectivité, qui s'incarne dans ce rapport au monde des insectes, existe de façon plus ou moins discrète dans notre civilisation. On se rend compte à un moment donné du roman, pour revenir à La Ruche d'Hellstrom, que la métaphore est paradoxalement vécue de manière positive autant que négative. Celui qui a créé cette ruche et cette nouvelle race humaine est aussi un bienfaiteur qui a construit cette ruche en opposition au monde extérieur, aux sauvages de l'extérieur, qui sont d'immondes destructeurs.

L'usage de la métaphore de l'abeille, dans les romans, est donc assez rare et elle est bien souvent vécue de manière répulsive. On peut aller plus loin : la sociobiologie (la sociologie des animaux) a pu, avec Herbert Spencer ou Alfred Espinas, entre la fin du XIX et le début $\mathrm{XX}^{\mathrm{e}}$ siècle, aboutir à des fusions-confusions entre la société humaine et la société animale, à des mécompréhensions voire à des dérives. Il est clair que la 


\section{Labyrinthe, $n^{\circ} 40$}

métaphore qu'utilise Yann Moulier Boutang autour de la pollinisation, si on la prend à la lettre et que l'on voit comment on a pu l'utiliser dans le monde des idées ou de la culture, apparaît comme un naturalisme qui présente des dangers, notamment de réductionnisme.

Si l'on prend la métaphore de la société des insectes, notamment celle des abeilles, dans une logique de tendances par rapport aux différents types d'époques, aux différents types de sociétés humaines, et à leurs évolutions, le regard change: Yann Moulier Boutang utilise la métaphore de l'abeille et de la pollinisation pour faire réfléchir sur notre aujourd'hui, avec en perspective à la fois le caractère vital de la pollinisation pour la vie sur Terre et l'immense cataclysme que fait peser sur nous l'horizon désormais envisageable de la disparition des abeilles. Mais il ne s'agit pas de dire que nous sommes des abeilles. La métaphore, prise avec ses nuances, devient un support à la réflexion. Sur ce registre, on peut avancer des idées qui vont nous permettre de penser, de manière caricaturale pour choquer ou à l'inverse très fine. Ainsi Serge Tisseron, un grand psychiatre et psychanalyste qui réfléchit sur les mondes virtuels aujourd'hui, donne-t-il comme clef l'idée que la culture du numérique, qui s'oppose à l'ancien monde de la culture de l'écrit, est une culture du multiple, du partage, par opposition à la culture de l'un, de la Bible, de l'auteur. Il écrit que ces logiques de partage se vivent de façon collective. Des métaphores animales peuvent nous aider à comprendre des évolutions de ce type - ce que ne fait pas Tisseron lui-même -, c'est-à-dire la façon dont le balancier évolue entre l'un et le multiple, l'individuel et le collectif. Dit autrement: dans ce nouveau monde internet, on avance vers un certain type de sociétés qui, d'une certaine façon, pourraient se rapprocher du monde des abeilles plus que de la centralisation démocratique de l'univers des lions. 
C'est pourquoi le ciel partage

la constitution de l'homme en diverses fonctions,

dont les efforts convergent par un mouvement continu

vers un résultat ou un but unique,

la subordination. Ainsi travaillent les abeilles,

créatures qui, par une loi de nature, enseignent

le principe de l'ordre aux monarchies populaires.

Elles ont un roi et des officiers de tout rang;

les uns, comme magistrats, sévissent à l'intérieur ;

d'autres, comme marchands, se hasardent à commercer au

[dehors;

d'autres, comme soldats, armés de leurs dards,

pillent les boutons de velours de l'été,

et avec une joyeuse fanfare rapportent leur butin

à la royale tente de leur empereur.

Lui, affairé dans sa majesté, surveille

les maçons chantants qui construisent des lambris d'or,

les graves citoyens qui pétrissent le miel,

les pauvres ouvriers porteurs qui entassent

leurs pesants fardeaux à son étroite porte,

le juge à l'œil sévère, au bourdonnement sinistre,

qui livre au blême exécuteur

le frelon paresseux et béant

William Shakespeare, Henry IV, acte I, scène 1, trad. fr. F.-V. Hugo, 1873. 